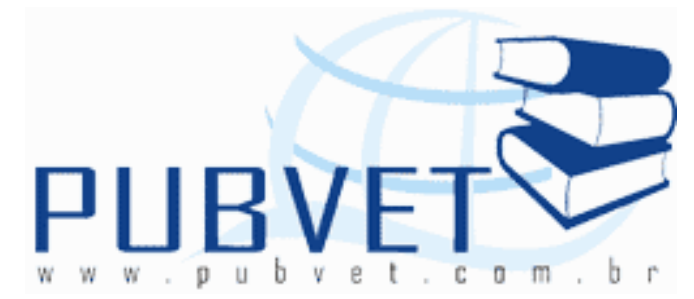

PUBVET, Publicações em Medicina Veterinária e Zootecnia.

\title{
Aspectos anátomo-histólogicos da cérvix em ovelhas Santa Inês
}

Lauro César Soares Feitosa ${ }^{1}$, Siluana Benvindo Ferreira ${ }^{1}$, Yânez André Gomes Santana ${ }^{1}$, Miguel Ferreira Cavalcante Filho ${ }^{2}$

${ }^{1}$ Universidade Federal do Piauí, Pós-Graduação em Ciência Animal, UFPITeresina

${ }^{2}$ Universidade Federal do Piauí, Departamento de Morfofisiologia Veterinária, Teresina- Piauí-Brasil

\section{Resumo}

Com o objetivo de caracterizar morfologicamente a cérvix de ovelhas visando ajudar na compreensão desta estrutura e conseqüentemente melhorar a eficiência reprodutiva da espécie, 22 cérvices de ovelhas não gestantes, da raça Santa Inês, com média de idade de $3,3 \pm 1,1$ anos e pesando entre 28 e $35 \mathrm{~kg}$ foram avaliadas macro e microscopicamente. Encontrou-se um

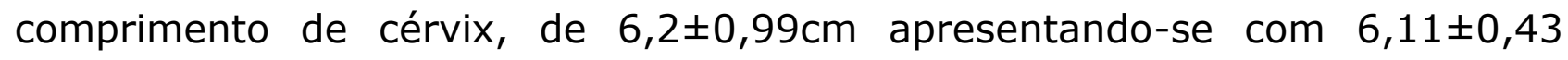
projeções circulares. Microscopicamente, apresentou uma camada de epitélio simples cilíndrico, seguida de uma camada de tecido conjuntivo frouxo $(1,5 \pm 0,27 \mathrm{~mm})$ e uma camada de tecido muscular liso $(4,5 \pm 1,23 \mathrm{~mm})$ no sentido circular. Após a camada muscular da mucosa, há uma camada de tecido muscular, no sentido longitudinal $(7,5 \pm 0,63 \mathrm{~mm})$. E finalmente, há uma camada serosa $(10 \pm 2,15 \mathrm{~mm})$ formada por fibras de tecido conjuntivo frouxo. Conclui-se que a cérvix de ovelhas da raça Santa Inês é delimitada por anéis 
FEITOSA, L.C.S. et al. Aspectos anátomo-histólogicos da cérvix em ovelhas Santa Inês. PUBVET, Londrina, V. 6, N. 19, Ed. 206, Art. 1380, 2012.

fibro-musculares, contendo pregas de mucosa de tamanho e ramificações variados.

Termos para indexação: morfologia, inseminação artificial, trato genital.

\section{Anatomic-histological aspects of the cervix in Santa Inês breed ewes}

\section{Summary}

In order to characterize morphologically the cervix of ewes to assist in understanding the structure and consequently improve the reproductive efficiency of the species, 22 non-pregnant Santa Inês breed cervix, with a mean age of $3.3 \pm 1.1$ years and weighing between 28 and $35 \mathrm{~kg}$ were evaluated macro and microscopically. We found a cervical length of $6.2 \pm 0.99$ $\mathrm{cm}$, thus with $6.11 \pm 0.43$ circular projections. Microscopically, had a layer of cilindric simple epithelium, followed by a layer of loose connective tissue (1.5 $\pm 0.27 \mathrm{~mm})$ and a layer of smooth muscle tissue $(4.5 \pm 1.23 \mathrm{~mm})$ to move. After the mucosal muscle layer, a layer of muscle tissue in the longitudinal direction $(7.5 \pm 0.63 \mathrm{~mm})$. And finally, there is a serous layer $(10 \pm 2.15 \mathrm{~mm})$ formed by fibers of loose connective tissue. It follows that the cervix of Santa Inês breed of sheep is surrounded by rings fiber-muscular, with folds of mucous membrane of varying size and ramifications.

Index terms: morphology, artificial insemination, genital tract.

\section{Introdução}

A Inseminação Artificial (I.A) vem sendo utilizada na ovinocaprinocultura, como ferramenta para minimizar custos com reprodutores e realizar um melhor ganho genético. Porém, é sabido das dificuldades da I.A via transcervical em ovelhas, constituindo-se como principal barreira para a inseminação uterina por esta via, a própria cérvix da espécie, a qual se caracteriza por possuir anéis excêntricos, que se adaptam um ao outro 
FEITOSA, L.C.S. et al. Aspectos anátomo-histólogicos da cérvix em ovelhas Santa Inês. PUBVET, Londrina, V. 6, N. 19, Ed. 206, Art. 1380, 2012.

reduzindo o diâmetro e ocluindo seguramente a passagem da cérvice (HAFEZ, 1995).

A cérvix representa a parte mais caudal do útero, servindo como meio de passagem entre a vagina e o útero, podendo ter tecido conjuntivo denso misturado ao músculo da cérvix, tornando-a uma parte não dilatável do trato genital na maioria das vezes (DYCE et al., 2002). Segundo Câmara, et al. (2002), supôs poder existir algum tecido cartilaginoso na cérvix de ovelhas sem raça definida.

Avaliando a eficiência da colheita transcervical de embriões em ovelhas Santa Inês, utilizando fármacos dilatadores, SILVA et al. (2004) concluiu que a técnica de colheita transcervical de embriões é possível em ovelhas pluríparas, mas que existe uma grande variação individual no grau de complexidade na transposição cervical.

Visando vencer as barreiras para esta prática, vários sistemas de I.A já foram avaliados utilizando-se métodos físicos, como insuflação da cérvice com CO2 (FUKUI \& ROBERTS, 2003), pipetas helicoidais ou de diferentes diâmetros e agulhas modificadas, as quais proporcionam alta freqüência de lesões segundo Câmara et al, (2002). Tentando ultrapassar a cérvix com instrumentos da inseminação artificial, Halbert et al. (1990), não obteve sucesso devido a não identificação da abertura cervical e dos orifícios menores das estruturas em forma de "anéis", encontrando estruturas cada vez mais consistentes a partir do segundo ou terceiro "anel".

Estando ciente da problemática exposta acima, ao tempo em que se considera a representatividade zootécnica desta espécie no rebanho Nordestino e Piauiense, e ainda da carência de literatura mais detalhada do assunto, esta pesquisa almeja estudar a estrutura anátomo-histológica da cérvix de ovelhas da raça Santa Inês, com a finalidade de fundamentar futuros estudos e aperfeiçoamento de técnicas ou ferramentas para Inseminações Artificiais e Coletas de Embriões via transcervical buscando-se aumentar a eficiência reprodutiva da raça. 
FEITOSA, L.C.S. et al. Aspectos anátomo-histólogicos da cérvix em ovelhas Santa Inês. PUBVET, Londrina, V. 6, N. 19, Ed. 206, Art. 1380, 2012.

\section{Material e Métodos}

Foram utilizadas 22 cérvices de ovelhas, não gestantes, da raça Santa Inês, com média de idade de 3,3 anos e pesando entre 28 e $35 \mathrm{Kg}$, adquiridas junto a criadores da cidade de Teresina - PI, para o estudo anatômico, utilizando-se de instrumentos cirúrgicos para dissecação das peças. Foram analisados: tamanho, morfologia externa e interna e medidas gerais.

As medidas gerais foram realizadas com as peças ainda frescas, utilizando-se paquímetro, iniciando pelo vestíbulo (da extremidade da comissura ventral da vulva até o óstio uretral externo), seguida da vagina (do óstio uretral externo ao óstio uterino externo) cérvix (do óstio uterino externo até o óstio uterino interno). Na cérvix, foram aferidos os seguintes parâmetros: espessura de parede, comprimento, número de anéis e comprimento do $1^{0}$ anel. A área da vagina foi aferida utilizando-se papel milimetrado.

Lâminas para análise em microscópio de luz de oito (8) cérvices foram produzidas utilizando o Laboratório de Anatomia animal como o de Histopatolgia Animal do Centro de Ciências Agrárias da Universidade Federal do Piauí, sendo feita a fixação do material em formaldeído a 4\%. Em seguida, procedeu-se a fragmentação do tecido em fragmentos de $1 \mathrm{~cm} \times 1 \mathrm{~cm} e$ desidratação em seqüência de álcoois ( 70, 85 e 95\% duas imersões de 20 minutos e em álcool absoluto em duas imersões de 30 minutos) em xilol (duas imersões de uma hora) e parafina (duas imersões de uma hora). Então, foi realizado o emblocamento dos tecidos em parafina de inclusão. Estes blocos foram submetidos aos processos de microtomia (micrótmo manual), onde foram feitos os "cortes" do tecido. Em seguida, as lâminas foram montadas, e posteriormente coradas com Hematoxilina e Eosina, sendo então realizada a montagem das lâminas, para a análise em microscópio de luz.

\section{Resultados e Discussão}

Morfologicamente, foi observado externamente, após a dissecação, uma divisão nítida na cérvix uterina, a qual se mostrou como um estreitamento 
FEITOSA, L.C.S. et al. Aspectos anátomo-histólogicos da cérvix em ovelhas Santa Inês. PUBVET, Londrina, V. 6, N. 19, Ed. 206, Art. 1380, 2012.

estendendo-se entre a vagina e o corpo do útero, cujos dados morfométricos revelaram médias de $6,2 \pm 0,99 \mathrm{~cm}$.

Neste trabalho para fins didáticos, este órgão foi dividido em três partes: caudal (divisão entre cérvix e vagina), intermediária e cranial (divisão entre cérvix e útero). Internamente, este órgão apresenta, em média, com $6,11 \pm 0,43$ projeções circulares, independentes e intercaladas, em forma de "cones" (Figura 01) que se dispõem transversalmente à luz do órgão, tornando o canal cervical irregular e sinuoso com projeções milimétricas em forma de dedos de luva que se projetam várias vezes em direção à passagem cervical.

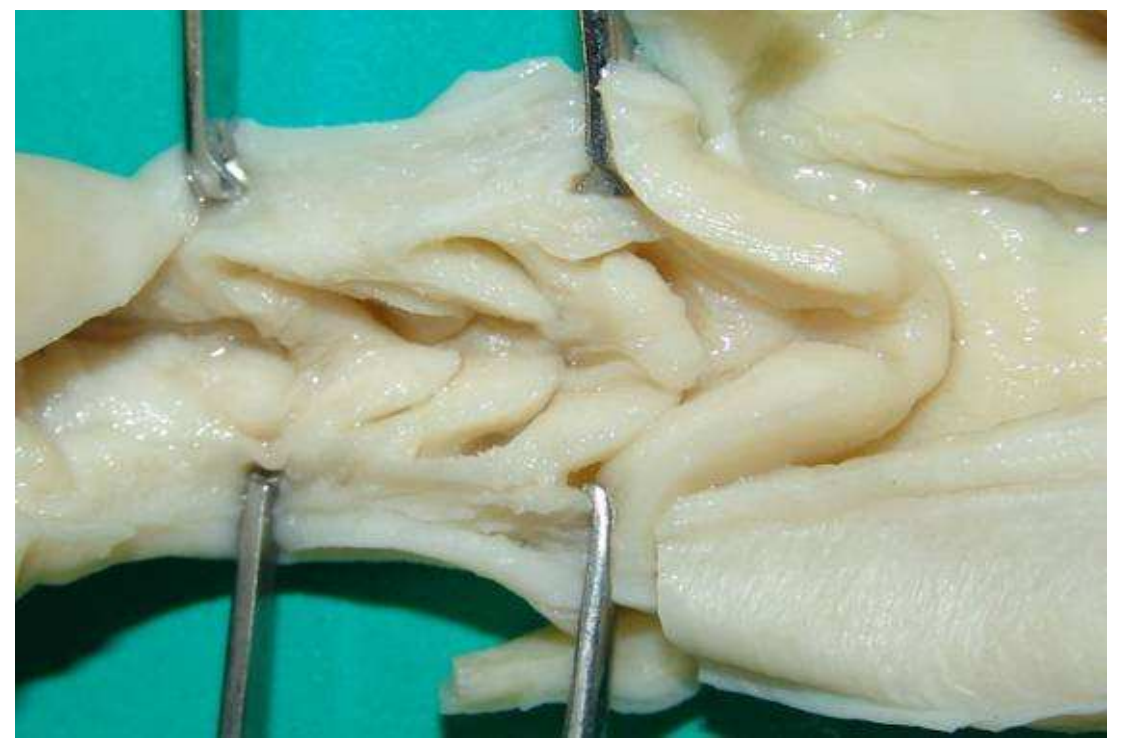

Figura 1. Cérvix uterina de ovelha da raça Santa Inês, mostrando os anéis fibro-musculares (Vista dorsal).

$\mathrm{Na}$ vagina, um destes anéis se projeta em média $1,4 \pm 0,5 \mathrm{~cm}$, e em $59,9 \%$ (13/22) dos animais, e é voltado ventralmente, diferindo dos achados de Mayor et al. (2004) em fêmeas de cateto (Tayassu tajucu) do nordeste da Amazônia, onde não ocorre o fato acima citado. Estes anéis se comportam de modo marcante no terço caudal e intermediário, se comportando como verdadeiros "cones" voltados distalmente, com seu eixo maior, variando tanto dorso-ventral como látero-lateral, ocasionado o não alinhamento dos orifícios. 
FEITOSA, L.C.S. et al. Aspectos anátomo-histólogicos da cérvix em ovelhas Santa Inês. PUBVET, Londrina, V. 6, N. 19, Ed. 206, Art. 1380, 2012.

No terço cranial, estes anéis se arrumam de modo menos compacto, ou seja, mais afastados entre si, ou estando incompletamente formados. Entre os anéis, podem-se notar fundos de saco cego, que podem ser confundidos com a luz do órgão; no momento da I.A transcervical, causando lesões na cérvix (ALMEIDA, 2002 e KERSHAW, 2005). Nestes anéis, pode-se notar macroscopicamente, pregas de mucosa em forma de vilosidades, que estão dispostas longitudinalmente, e são encontradas em toda a extensão dos anéis.

Microscopicamente, estes anéis são formados quase completamente por tecido conjuntivo frouxo e a túnica muscular formada por projeções de tecido muscular liso, semelhante ao de roedores africanos (Atherurus africanus) segundo Mayor et al. (2002). Em contato com a luz do órgão há uma camada de epitélio cúbico simples (Figura 02). Logo após esta camada, há uma camada de tecido conjuntivo frouxo medindo $1,5 \pm 0,27 \mathrm{~mm}$, seguida de uma camada de tecido muscular liso $(4,5 \pm 1,23 \mathrm{~mm})$ no sentido circular.

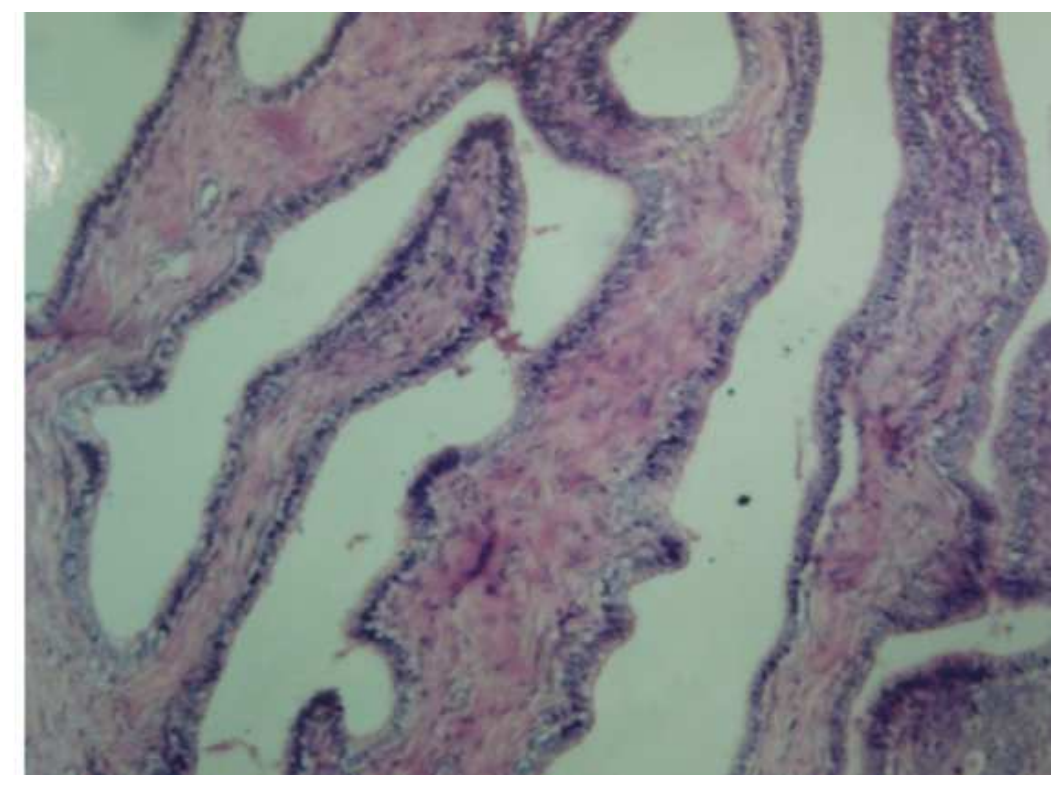

Figura 2. Corte transversal do segmento intermediário da cérvix uterina de ovelha da raça Santa Inês. Notar epitélio simples cilíndrico (E) e pregas da mucosa bem ramificada. 
FEITOSA, L.C.S. et al. Aspectos anátomo-histólogicos da cérvix em ovelhas Santa Inês. PUBVET, Londrina, V. 6, N. 19, Ed. 206, Art. 1380, 2012.

Estas pregas de mucosa de acordo com a região da cérvix são mais desenvolvidas e ramificadas (Intermediária e Cranial). São formadas por um epitélio cúbico simples, fibras de tecido conjuntivo frouxo e fibras de tecido muscular liso, que provém da camada de tecido muscular liso da mucosa, sendo estas pregas muito pobres em vasos e nervos, o que diminui a sua capacidade secretora e de absorção. Entre estas pregas há várias glândulas do tipo tubular simples, que desembocam na luz do órgão.

(Figura 03).

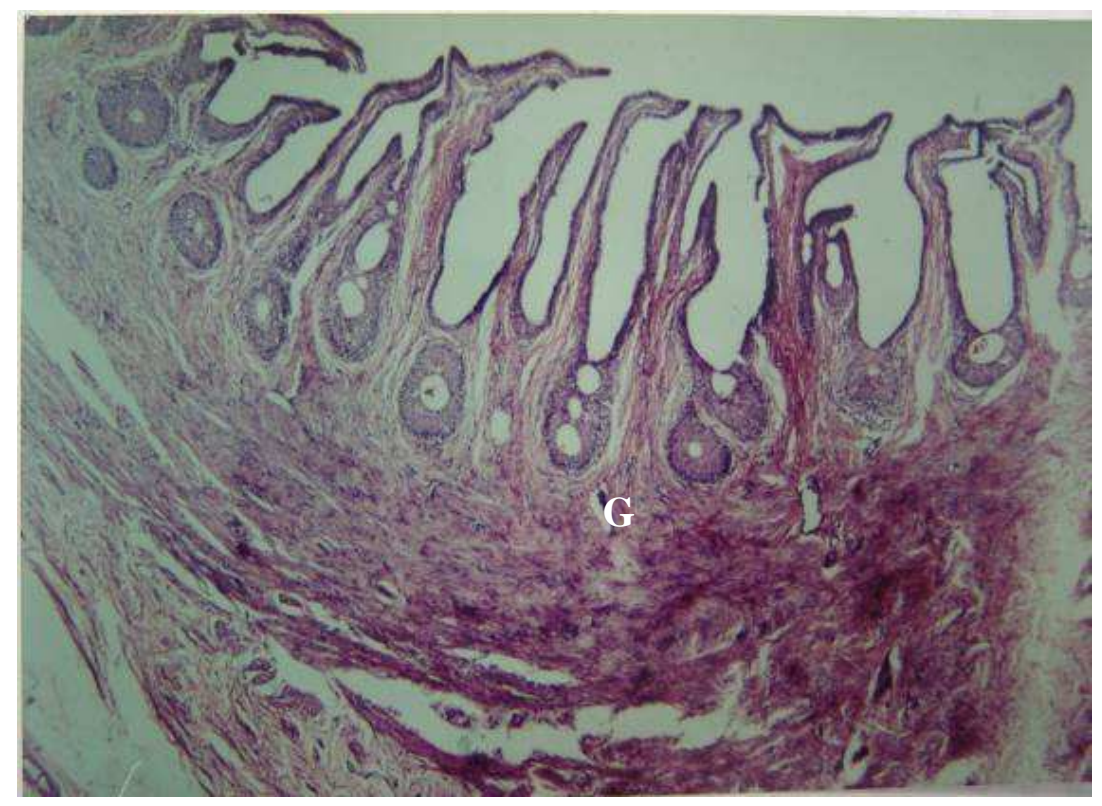

Figura 3. Corte transversal do segmento caudal da cérvix uterina de ovelha Santa Inês. Notar as glândulas (G) entre as pregas de mucosa.

Após a camada muscular da mucosa há uma camada de tecido muscular, no sentido longitudinal (Figura 04), que não pode ser visualizada completamente, denotando não contornar a circunferência completa da cérvix. Esta camada pode ser visualizada de modo bem característico na parte caudal $(7,0 \pm 0,2 \mathrm{~mm})$ e na cranial $(8,0 \pm 0,13 \mathrm{~mm})$, não sendo possível visualizá-la na parte intermediária. 


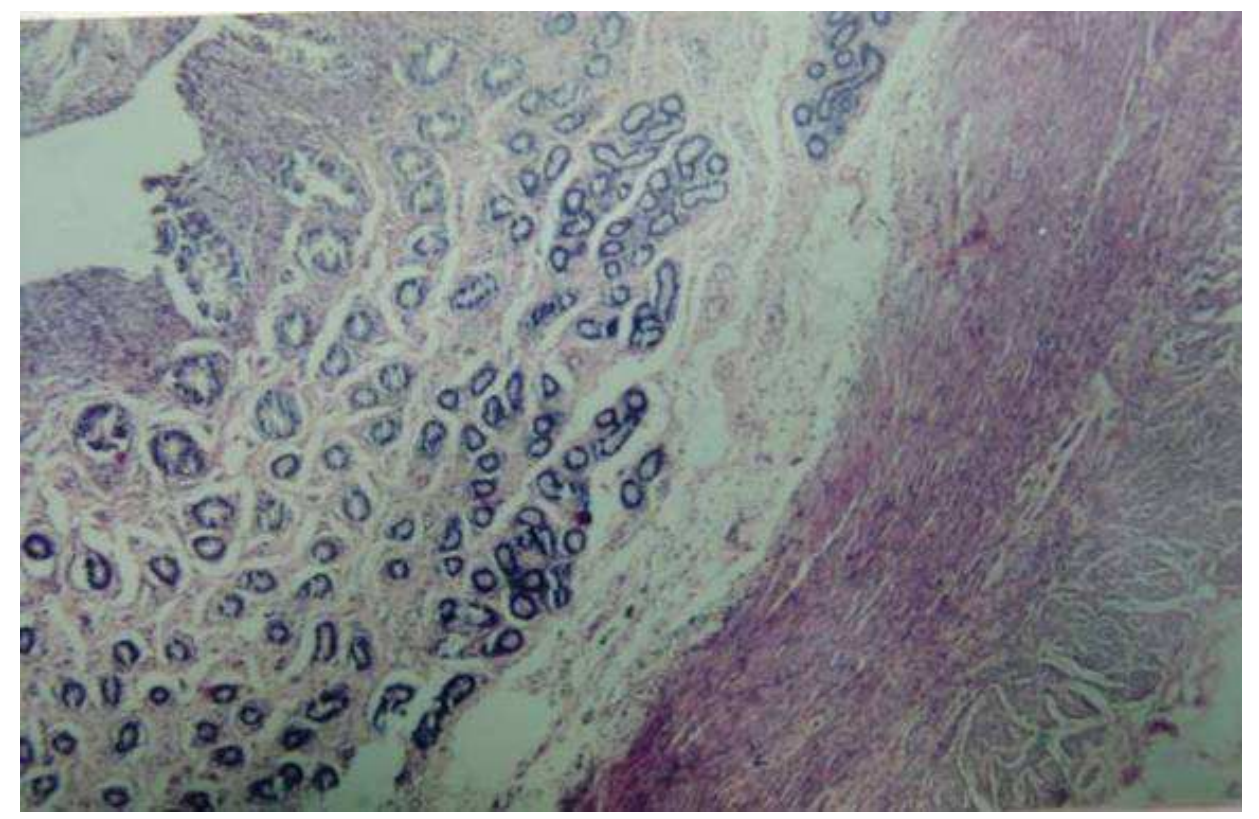

Figura 4. Corte transversal da parte cranial da cérvix uterina de ovelha da raça Santa Inês, mostrando glândulas de muco na submucosa (GL) uma camada muscular da mucosa (MM) circular e uma camada muscular longitudinal (ML).

Pode ser notada na parte proximal uma grande quantidade de glândulas de muco, com paredes bem tortuosas e luz dilatada, devido acúmulo de secreção. E finalmente, há uma camada serosa $(10$ Е̌, $15 \mathrm{~mm})$ formada por fibras de tecido conjuntivo frouxo e bastante vascularizada.

\section{Consideração Final}

Portanto, conclui-se que a cérvix uterina ovina, mais especificamente da raça Santa Inês, possui uma luz bem constricta e tortuosa, que é delimitada por anéis fibro-musculares (média de seis); anéis estes, que em sua parte de contacto com a luz, possuem pregas de mucosa, que se apresentam em número, tamanho e quantidade de ramificações, variando de acordo com a região do órgão. 


\section{Referências Bibliográficas}

ALMEIDA,V.M. et al. Colheita de embriões por via transcervical em ovinos. Revista Brasileira de Reprodução Animal, n.5, p.82-84, 2002.

CÂMARA, D.R. et al. Inseminação artificial por via transcervical com sêmen congelado em ovinos deslanados sem raça definida (SRD). Revista Brasileira de Reprodução Animal n.5, p.88-92, 2002.

CAVACO - GONÇALVES, S. et al. Increased cervical electrical activity during oestrus in progestagen treated ewes: Possible role in sperm transport. Animal Reports Science. v.93, n.3, p.360-365, 2006.

DYCE, K.M; SACK, W.O; WENSING , C.I.G. Tratado de Anatomia Veterinária. $3^{a}$ ed.: Elsevier. São Paulo - SP, 2002, p.194.

FUKUI, Y.; ROBERTS, E.M. Further studies on non-surgical intrauterine technique for a artificial insemination in the ewe. Theriogenology, v.10, n.5, p.381-393, 1978.

HALBERT, G.W. et al. The structure of the cervical canal of the ewe. Theriogenology, v.33, n.5, p.977-992, 1990.

HAFEZ, E.S.E. Reprodução Animal. Anatomia do trato reprodutivo de fêmeas adultas vazias de ovelhas. $6^{a}$ ed.: Manole Ltda. São Paulo - SP. P.33.

KERSHAW, C.M. et al. The anatomy of the sheep cervix and its influence on the transcervical passage of an inseminating pipette into the uterine lumen. Theriogenology, v.64, n.5, p.1225-1235, 2005.

MAYOR, P. et al. Anatomicohistological characteristics of the genital tubular organs of the female Brush-tailed Porcupine (Atherurus africanus, Grey 1842) from Gabon. Anatomia Histologia e Embryologia, v.31, p.355-361, 2002.

NAQVI, S.M.K. et al. Evaluation of gross anatomical features of cervix of tropical sheep using cervical silicone moulds. Animal Reports Science, v, 85, n. 3-4, p.337-344, 2005.

SILVA, J.C. et al. Avaliação da colheita transcervical de embriões ovinos da raça Santa Inês. Acta Scientiae Veterinariae. v32, p.90, 2004. 